\title{
A hospital based plain radiographic observational study of lumbosacral transitional vertebrae in the Nepalese population
}

\author{
Manoj Bhattarai \\ Associate Professor, Department of Radiodiagnosis and Imaging, B.P. Koirala Institute of Health Sciences, Dharan, \\ Sunsari, Nepal
}

\section{A B S T R A C T}

Background: Presence of lumbosacral transitional vertebra may lead to number of clinical consequences because of failure to correctly number the problematic vertebra and also has been associated with low back pain. Different studies done at different part of the world have shown wide range of prevalence of lumbosacral transitional vertebra. Aims and Objective: This hospital based cross sectional observational study was undertaken to determine the prevalence of lumbosacral transitional vertebra among the Nepalese population.Materials and Methods: Plain radiographs (anteroposterior and lateral views of lumbosacral spine and KUB radiographs) of 947 patients (646 with lumbosacral spine and 301 with KUB radiographs) done from August 2015 to July 2016 and meeting inclusion criteria were retrospectively analyzed for the presence of lumbosacral transitional vertebra. Results: The overall prevalence of lumbosacral transitional vertebra was $14.7 \%$ with prevalence of $16.3 \%$ in patients with lumbosacral radiographs and $11.3 \%$ in patients with KUB radiographs and was statistically significant. Prevalence of sacralization was higher than lumbarization $(11.9 \% \mathrm{Vs} 2.7 \%)$. Lumbosacral transitional vertebra was more common in females than in males with Castellvi type I being most common and type IV least common. Conclusion: The overall prevalence of lumbosacral transitional vertebra in the studied Nepalese population was $14.7 \%$ with significantly higher prevalence in patients with lumbosacral radiographs than with KUB radiographs.

Key words: Lumbarization; Lumbosacral transitional vertebra; Nepalese population; Plain radiographs; Sacralization

\section{INTRODUCTION}

Lumbosacral transitional vertebra (LSTV), with a wide range of prevalence from $4 \%$ to $35.9 \%$ and a mean prevalence of $12.3 \%$ as reported in different studies, is a common congenital anomaly of lumbosacral vertebral junction that presents either as sacralization of fifth lumbar (L5) vertebra (elongated and broadened L5 transverse processes to its fusion with sacrum) or lumbarization of first sacral (S1) vertebra (separation of S1 vertebra from remaining sacral vertebrae). ${ }^{1-4}$ Identification of LSTV is important as its presence may lead to number of clinical consequences like performing spinal surgery at wrong level, errors in other lumbosacral procedures and poor correlation of patients symptoms because of failure to correctly number the problematic vertebra. ${ }^{4}$ Association between presence of LSTV and low back pain (also known as Bertolotti syndrome) was first described by Bertolotti in 1917, 1,5 which is still controversial and debatable as the results of various studies are conflicting with some studies showing positive correlation, ${ }^{6-10}$ while no association was found in others. ${ }^{11-14}$ However higher occurrence of disc herniation or degenerative changes immediately above the level of LSTV has been reported. ${ }^{12,14-16}$ 
Even though detection of LSTV can be made in various imaging modalities including plain radiographs, computed tomography (CT) and magnetic resonance imaging (MRI), there is no well established standard technique to identify and number LSTV. Ferguson radiograph which is anteroposterior radiograph with 30 degrees cranial angulation has been regarded as best for identifying LSTV, but currently role of CT and MRI in this regard have been evaluated. Due to risk of exposure to radiation CT scans are not routinely recommended for sole purpose of evaluation of LSTV. Also determination of LSTV with MRI alone may be challenging when plain radiographs are not available. On MRI different studies have suggested various techniques to number the lumbar vertebrae, of which use of iliolumbar ligament as a landmark is considered to be more accurate. ${ }^{1,4,17,18}$

As different studies done at different part of the world have shown wide range of prevalence of LSTV, knowledge of local prevalence is important so as to avoid any untoward consequences during patient management due to failure to accurately assign the vertebral number. Hence this hospital based study was undertaken to determine the prevalence of LSTV in the Nepalese population.

\section{MATERIAL AND METHODS}

In this cross sectional observational study, plain radiographs (anteroposterior and lateral views of lumbosacral spine and KUB radiographs) of 947 patients done from August 2015 to July 2016 in Department of Radiodiagnosis and Imaging of Nobel Medical College Teaching Hospital (NMCTH), Biratnagar and meeting inclusion criteria were retrospectively analyzed for the presence of lumbosacral transitional vertebra. Of the plain radiographs of 947 patients studied, 646 were of lumbosacral spine and 301 of KUB. Patients of both sexes and all age groups were included in the study. Radiographs of poor image quality hampering adequate evaluation of all lumbosacral vertebrae (mainly transverse processes); not including last thoracic vertebra with rib attached to it and with presence of vertebral fracture, signs of spinal surgery and/or vertebral destruction due to tumor or infection were excluded from the study. First of all twelfth thoracic (T12) vertebra was identified, which was defined as the vertebra to which the lowest rib is attached and then numbering of lumbar vertebrae was done craniocaudally with the vertebra immediately below T12 vertebra numbered as first lumbar (L1) vertebra ${ }^{1}$ thus noting presence or absence of LSTV. When present, LSTV were further classified according to the Castellvi radiographic classification ${ }^{4,19}$ into four types as follows:

Type I: Enlarged and dysplastic transverse process(es), measuring $\geq 19 \mathrm{~mm}$ in width (craniocaudal dimension). Ia - Unilateral, Ib - Bilateral.
Type II: Incomplete lumbarization/sacralization with an enlarged transverse process(es) and pseudoarticulation of the transverse process(es) and the sacrum. IIa Unilateral, IIb - Bilateral.

Type III: Lumbarization/sacralization with complete bony fusion of the transverse process(es) to the sacrum. IIIa - Unilateral, IIIb - Bilateral.

Type IV: Mixed type. A unilateral type II transition with a type III on the contralateral side.

All of these four types of LSTV were included in this study. Record was made of patients age, gender and findings of lumbosacral vertebrae including number of lumbar vertebrae, craniocaudal measurement of transverse process of L5 vertebra and pseudoarthrosis and/or bony fusion of L5 vertebral transverse process(es) with the sacrum.

For statistical analysis acquired data were entered on Microsoft Excel worksheet and then using IBM SPSS statistics 20 software further analysis was done. Frequency, percentage and mean with standard deviation were calculated for various categorical and numerical variables. Chi-square test was applied to examine association between two categorical variables with $\mathrm{p}$-value $<0.05$ considered to be significant.

\section{RESULTS}

Plain radiographs of 947 patients were studied which included $646(68.2 \%)$ radiographs of lumbosacral spine and $301(31.8 \%)$ of KUB. Of these, $452(47.7 \%)$ were male and $495(52.3 \%)$ female with male to female ration of 1:1.17. Mean age of the patients included in this study at the time of imaging was $44.9 \pm 15.6$ years (range $15-88$ years).

Out of the total 947 patients, LSTV was seen in $139(14.7 \%)$. LSTV was found to be more common in females with its distribution of $64(46.0 \%)$ in males and $75(54.0 \%)$ in females and a prevalence of $14.1 \%$ and $15.1 \%$ in males and females respectively. This difference in prevalence of LSTV between males and females was statistically insignificant $(\mathrm{p}$ value $=0.666)$.

According to Castellvi classification of LSTV, type I was seen in $61(43.9 \%)$, type II in $42(30.2 \%)$, type III in $26(18.7 \%)$ and type IV in $10(7.2 \%)$ of patients. (Figure 1$).$

Of the 139 patients with LSTV, $113(81.3 \%)$ had sacralization whereas lumbarization was seen in $26(18.7 \%)$ patients with overall prevalence of sacralization and lumbarization being $11.9 \%$ and $2.7 \%$ respectively. Sacralization was commonly seen in males than in females (55 (85.9\%) Vs $58(77.3 \%)$ ), while lumbarization was common in females $(17(22.7 \%)$ Vs $9(14.1 \%))$. However this gender difference in sacralization 
and lumbarization was statistically insignificant ( $\mathrm{p}$ value $=0.830$ and 0.174 respectively). (Table 1)

Out of 139 LSTV, 105 (75.5\%) were seen in lumbosacral radiographs and the remaining $34(24.5 \%)$ in radiographs of KUB. Overall LSTV was noted in $16.3 \%$ of patients with lumbosacral radiographs in comparison to $11.3 \%$ with KUB radiographs. This difference in presence of LSTV in lumbosacral and KUB radiographs was statistically significant $(\mathrm{p}$ value $=0.044) .($ Table 2$)$

\section{DISCUSSION}

A common congenital anomaly of lumbosacral junction, LSTV has a wide range of prevalence from $4 \%$ to $35.9 \%$ in different study population as reported in literature. ${ }^{1}$ This variation in prevalence has been attributed to differences in the number of factors taken into consideration while conducting a study, like definition, criteria and classification of transitional vertebra; type of study population, whether

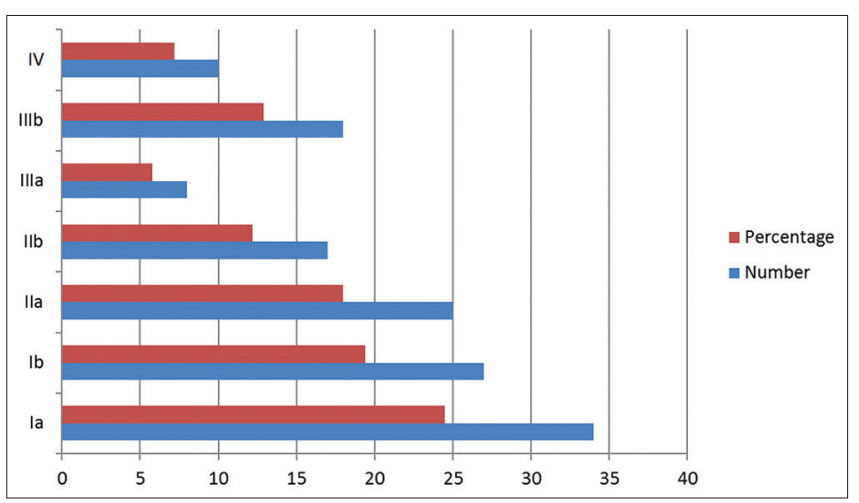

Figure 1: Frequency of LSTV according to Castellvi classification with low back pain (LBP) or not; imaging technique used; error of observer and other study population related confounding factors. ${ }^{1,8,16,18,20,21}$ Erken et al, ${ }^{3}$ Nardo et al ${ }^{8}$ and Uçar D et a ${ }^{20}$ included Castellvi type I LSTV in their study, while Hsieh et al, ${ }^{2}$ Sekharappa et a ${ }^{16}$ and French et a ${ }^{18}$ did not included it, as they considered Castellvi type I to be a normal anatomical variation lacking clinical significance. In this study all four types of LSTV according to Castellvi radiographic classification were included.

Evaluation of LSTV was done in KUB radiographs by Khashoggi et $\mathrm{al}^{21}$ and Apazidis et $\mathrm{al}^{22}$; lumbosacral radiographs by French et $\mathrm{al}^{18}$ and Uçar BY et $\mathrm{al}^{23}$; abdominal radiographs by $\mathrm{Uçar} \mathrm{D}$ et $\mathrm{al}^{20}$; KUB, lumbosacral radiographs and MRI by Sekharappa et a ${ }^{16}$ and lumbosacral, KUB and abdominal radiographs by $\mathrm{Garg}^{24}$. This study evaluated plain radiographs of both lumbosacral spine and KUB for the presence of LSTV.

In this study, the overall prevalence of LSTV in the studied Nepalese population was $14.7 \%$ with higher prevalence in females in comparison to males. However this gender variation in prevalence of LSTV was statistically insignificant. In another MRI based study from Nepal by Karki et $\mathrm{al}^{25}$ LSTV was seen in $3.8 \%$ of patient, which was much lower than that noted in this study. Similarly LSTV prevalence of $10.0 \%$ was reported in north Indian population by $\mathrm{Garg}^{24}$ from evaluation of lumbosacral, KUB and abdomen radiographs. Higher prevalence of LSTV in females was also found in study of Sekharappa et $a 1,{ }^{16}$ whereas Nardo et al, ${ }^{8}$ Uçar D et al ${ }^{20}$ and Uçar BY et $\mathrm{al}^{23}$ reported higher LSTV prevalence in males than in females. The most common type of LSTV observed in this study was Castellvi type I with type IV being least common,

\begin{tabular}{lccrr}
\multicolumn{4}{l}{ Table 1: Distribution of sacralization and lumbarization according to gender } \\
\hline LSTV & Male $(\mathbf{n}=\mathbf{6 4})(\mathbf{\%})$ & Female $(\mathbf{n}=\mathbf{7 5}) \mathbf{( \% )}$ & Total (n= 139) (\%) & P value* \\
\hline Sacralization & $55(85.9)$ & $58(77.3)$ & $113(81.3)$ & 0.830 \\
Lumbarization & $9(14.1)$ & $17(22.7)$ & $26(18.7)$ & 0.174 \\
Total & $64(100)$ & $75(100)$ & $139(100)$ & 0.666 \\
\hline
\end{tabular}

*Chi square test

\section{Table 2: Distribution of findings according to LSTV and radiograph types}

\begin{tabular}{|c|c|c|c|c|}
\hline Findings & Lumbosacral radiograph $(n=646)(\%)$ & KUB radiograph $(n=301)(\%)$ & Total $(n=947)(\%)$ & P value* \\
\hline No LSTV & $541(83.7)$ & $267(88.7)$ & $808(85.3)$ & \\
\hline LSTV present & $105(16.3)$ & $34(11.3)$ & $139(14.7)$ & $0.044^{* *}$ \\
\hline la & $26(4.0)$ & $8(2.6)$ & $34(3.6)$ & \\
\hline $\mathrm{lb}$ & $21(3.3)$ & $6(2.0)$ & $27(2.9)$ & \\
\hline Ila & $19(2.9)$ & $6(2.0)$ & $25(2.6)$ & \\
\hline $\mathrm{Ilb}$ & $13(2.0)$ & $4(1.3)$ & $17(1.8)$ & \\
\hline IIla & $5(0.8)$ & $3(1.0)$ & $8(0.8)$ & \\
\hline IV & $8(1.2)$ & $2(0.7)$ & $10(1.1)$ & \\
\hline
\end{tabular}

*Chi square test, **Statistically significant 
which was similar as seen in study of Nardo et $a l^{8}$ but in different proportions.

According to literature, the overall prevalence of sacralization is higher than that of lumbarization, ${ }^{1}$ which also holds true for this study with the prevalence of $11.9 \%$ and $2.7 \%$ for Sacralization and lumbarization respectively. Sacralization was common than lumbarization in the study of Steinberg et al, ${ }^{10}$ Sekharappa et al, ${ }^{16}$ Hughes et al, ${ }^{17}$ Uçar D et al, ${ }^{20}$ Khashoggi et al, ${ }^{21}$ Uçar BY et al, ${ }^{23}$ Garg, ${ }^{24}$ and Santiago et al, ${ }^{26}$ whereas lumbarization was reported to be common by French et al, ${ }^{18}$ Leboeuf et $\mathrm{al}^{27}$ and Peh et $\mathrm{al}^{28}$. According to French et $\mathrm{al}^{18}$ the reason given for higher prevalence of lumbarization in their study was may be due to exclusion of type I LSTV causing in decrease in their recorded prevalence of sacralization. Wide range in prevalence of sacralization and lumbarization has been noted in analysis of different studies. The prevalence of sacralization and lumbarization was $14.0 \%$ and $4.3 \%$, $11.0 \%$ and $2.0 \%, 9.2 \%$ and $4.2 \%, 3.8 \%$ and $5.3 \%, 17.2 \%$ and $1.7 \%, 21.2 \%$ and $2.4 \%, 11.6 \%$ and $7.2 \%, 5.5 \%$ and $6.0 \%$ \& $6.2 \%$ and $7.0 \%$ in the studies of Steinberg et al, ${ }^{10}$ Sekharappa et al, ${ }^{16}$ Hughes et al, ${ }^{17}$ French et al, ${ }^{18}$ Uçar D et al, ${ }^{20}$ Uçar BY et al, ${ }^{23}$ Santiago et al, ${ }^{26}$ Leboeuf et al, ${ }^{27}$ \& Peh et $\mathrm{al}^{28}$ respectively with the range of $3.8 \%-21.2 \%$ for sacralization and $1.7 \%-7.2 \%$ for lumbarization. Hence the prevalence of sacralization (11.9\%) and lumbarization $(2.7 \%)$ as seen in this study falls within the above mentioned range. Gender difference in occurrence of sacralization and lumbarization was noted with sacralization common in males than in females $(85.9 \%$ Vs $77.3 \%)$ and lumbarization common in females than in males $(22.7 \%$ Vs $14.1 \%)$, but was statistically insignificant. This finding of gender variation in occurrence of sacralization and lumbarization in this study was in concordance with the result of studies by Uçar D et al, ${ }^{20}$ Khashoggi et al ${ }^{21}$ and Mahato ${ }^{29}$.

The prevalence of LSTV was higher in the patients with lumbosacral radiographs than with KUB radiographs $(16.3 \%$ Vs $11.3 \%)$. This difference was statistically significant and was in agreement with the study of Sekharappa et al. ${ }^{16}$ Higher prevalence of LSTV in the patients with lumbosacral radiographs than with KUB radiographs may be due to additional advantage of lateral view aiding in identification of LSTV in the patients with lumbosacral radiograph. Also as the lumbosacral radiographs are mainly taken in patients presenting with clinical symptoms pertaining to vertebral column particularly LBP, there might be some relationship between the presence of LSTV and LBP. Similarly the radiographs of KUB are indicated for other clinical symptoms rather than for LBP, hence KUB radiographs may closely represent for the general population (although not an ideal or true representation) than for the patients with
LBP. As the clinical symptoms and the exact indication of lumbosacral and KUB radiographs in these patients were not known, the relationship between LSTV and LBP could not be associated confidently in this study. Therefore to determine the causal relationship between LSTV and LBP further large scale prospective study taking consideration of patients clinical symptoms should be carried out.

\section{Limitations of the study}

As this was a hospital based single institutional study, the findings may not represent the entire population. Similarly the study population was the patients visiting hospital for treatment; the results may not truly reflect the findings of normal general population. Also exclusion of radiographs due to various technical factors may have an erroneous effect in calculation of prevalence of LSTV.

\section{CONCLUSION}

The overall prevalence of LSTV in the studied Nepalese population was $14.7 \%$ with significantly higher prevalence in patients with lumbosacral radiographs than with KUB radiographs. As LSTV is a common congenital anomaly of lumbosacral vertebral junction, its identification and thus accurate assignment of vertebral number is important to avoid any untoward consequences during patient management.

\section{REFERENCES}

1. Bron JL, van Royen BJ and Wuisman PI. The clinical significance of lumbosacral transitional anomalies. Acta Orthop Belg 2007;73:687-695.

2. Hsieh CY, Vanderford JD, Moreau SR and Prong T. Lumbosacral transitional segments: classification, prevalence, and effect on disk height. J Manipulative Physiol Ther 2000;23:483-489.

3. Erken E, Ozer HT, Gulek B and Durgun B. The association between cervical rib and sacralization. Spine 2002;27:1659-1664.

4. Konin GP and Walz DM. Lumbosacral Transitional Vertebrae: Classification, Imaging Findings, and Clinical Relevance. Am J Neuroradiol 2010;31:1778-1786.

5. Bertolotti M. Contributo alla conoscenza dei vizi di differenzazione regionale del rachide con speciale riguardo all assimilazione sacrale della v. lombare. Radiol Med 1917;4:113-144.

6. Tang M, Yang XF, Yang SW, Han P, Ma YM, Yu H, et al. Lumbosacral transitional vertebra in a population-based study of 5860 individuals: prevalence and relationship to low back pain. Eur J Radiol 2014; 83:1679-1682.

7. Dai L. Lumbosacral transitional vertebrae and low back pain. Bull Hosp Jt Dis 1999; 58:191-193.

8. Nardo L, Alizai H, Virayavanich W, Liu F, Hernandez A, Lynch JA, et al. Lumbosacral transitional vertebrae: association with low back pain. Radiology 2012; 265:497-503.

9. Quinlan JF, Duke D and Eustace S. Bertolotti's syndrome. A cause of back pain in young people. J Bone Joint Surg 2006; 88-B: 1183-1186.

10. Steinberg EL, Luger E, Arbel R, Menachem A and Dekel S. 
A comparative roentgenographic analysis of the lumbar spine in male army recruits with and without lower back pain. Clin Radiol 2003;58:985-989.

11. Luoma K, Vehmas T, Raininko R, Luukkonen R and Riihimäki H. Lumbosacral transitional vertebra: relation to disc degeneration and low back pain. Spine 2004; 29:200-205.

12. Paajanen $\mathrm{H}$, Erkintalo $\mathrm{M}$, Kuusela $\mathrm{T}$, Dahlstrom $\mathrm{S}$ and Kormano M. Magnetic resonance study of disc degeneration in young low-back pain patients. Spine 1989; 14:982-985.

13. Peterson CK, Bolton J, Hsu W and Wood A. A cross-sectional study comparing pain and disability levels in patients with low back pain with and without transitional lumbosacral vertebrae. J Manipulative Physiol Ther 2005; 28:570-574.

14. Elster AD. Bertolotti's syndrome revisited. Transitional vertebrae of the lumbar spine. Spine 1989; 14:1373-1377.

15. Otani K, Konno $\mathrm{S}$ and Kikuchi S. Lumbosacral transitional vertebrae and nerve-root symptoms. J Bone Joint Surg 2001; 83-B:1137-1140.

16. Sekharappa V, Amritanand R, Krishnan V and David KS. Lumbosacral Transition Vertebra: Prevalence and Its Significance. Asian Spine J 2014; 8:51-58.

17. Hughes RJ and Saifuddin A. Numbering of lumbosacral transitional vertebrae on MRI: role of the iliolumbar ligaments. AJR Am J Roentgenol 2006; 187(1):W59-W65.

18. French HD, Somasundaram AJ, Schaefer NR and Laherty RW. Lumbosacral Transitional Vertebrae and Its Prevalence in the Australian Population. Global Spine J 2014; 4:229-232.

19. CastellviAE, Goldstein LA and Chan DP. Lumbosacral transitional vertebrae and their relationship with lumbar extradural defects. Spine 1984; 9:493-495.

20. Uçar D, Uçar BY, Cosar Y, Emrem K, Gümüssuyu G,
Mutlu S, et al. Retrospective cohort study of the prevalence of lumbosacral transitional vertebra in a wide and well-represented population. Arthritis 2013; 2013:461425.

21. Khashoggi KG, Hafiz RM, Bock YM and Kaki AM. Determination of lumbosacral transitional vertebrae in kidney urinary bladder x-ray films in the Saudi population. Saudi Med J 2017; 38:794-797.

22. Apazidis A, Ricart PA, Diefenbach CM and Spivak JM. The prevalence of transitional vertebrae in the lumbar spine. Spine $\mathrm{J}$ 2011; 11:858-862.

23. Uçar BY, Uçar DE, Bulut M, Azboy İ and DemirtaşA. Lumbosacral Transitional Vertebrae in Low Back Pain Population. J Spine 2013; 2:125.

24. Garg R. Association of radiographic and MRI in patients with lumbosacral transitional vertebra with or without backache. EPOS [Internet]. 2017 [cited 2018 April 9].

25. Karki DB, Panta OB and Gurung G. MRI Findings of NonDegenerative Pathoanatomical Changes in Low Back Pain. NJNS 2015; 12:59-62.

26. Santiago FR, Milena GL, Herrera RO, Romero PAand Plazas PG. Morphometry of the lower lumbar vertebrae in patients with and without low back pain. Eur Spine J 2001; 10:228-233.

27. Leboeuf C, Kimber D and White K. Prevalence of spondylolisthesis, transitional anomalies and low intercrestal line in a chiropractic patient population. J Manipulative Physiol Ther 1989; 12:200-204.

28. Peh WC, Siu TH and Chan JH. Determining the lumbar vertebral segments on magnetic resonance imaging. Spine 1999; 24:1852-1855

29. Mahato NK. Relationship of sacral articular surfaces and gender with occurrence of lumbosacral transitional vertebrae. Spine J 2011; 11: 961-965.

\section{Author's Contribution:}

MB- Concept and design of study, literature review, data collection, statistical analysis and interpretation, manuscript preparation, editing and critical revision of manuscript.

Orcid ID:

Dr. Manoj Bhattarai - (D http://orcid.org/0000-0003-4261-7933

Work attributed to: Department of Radiodiagnosis and Imaging of Nobel Medical College Teaching Hospital (NMCTH), Biratnagar, Morang, Koshi, Nepal.

Source of Support: Nil, Conflict of Interest: None declared. 